03,05

\title{
Магнетосопротивление и ИК-спектр примесных состояний в пленке $\mathrm{Ce}_{3} \mathrm{Fe}_{5} \mathrm{O}_{12}$
}

\author{
(C) С.С. Аплеснин ${ }^{1,2}$, А.Н. Масюгин ${ }^{1}$, В.В. Кретинин ${ }^{1}$, С.О. Коновалов ${ }^{1}$, Н.П. Шестаков ${ }^{2}$ \\ ${ }^{1}$ Сибирский государственный университет науки и технологий им. М.Ф. Решетнева, \\ Красноярск, Россия \\ ${ }^{2}$ Институт ффизики им. Л.В. Киренского, обособленное подразделение ФИЦ КНЦ СО РАН, \\ Красноярск, Россия \\ E-mail: apl@iph.krasn.ru
}

Поступила в Редакцию 18 октября 2020 г.

В окончательной редакции 18 октября 2020 г.

Принята к публикации 20 октября 2020 г.

В поликристаллических пленках цериевого феррита граната найдена величина щели в спектре электронных возбуждений, электронные переходы между примесными двухвалентными и четырехвалентными ионами железа и церия из ИК-спектров поглощения. Найдены температуры делокализации двухвалентных состояний железа из импедансной спектроскопии, электросопротивления и ИК-спектров. Найдено отличие магнитосопротивления на переменном и постоянном токе, которое объясняется в модели диэлектрически неоднородной среды.

Ключевые слова: магнитоимпеданс, ИК-спектроскопия, цериевый феррит гранат, тонкие пленки.

DOI: 10.21883/FTT.2021.02.50466.222

\section{1. Введение}

Пленки феррит-гранатов с редкоземельными катионами обладают потенциальной возможностью использования в магнитооптике [1-3], в том числе магнитоплазмонной фотонике [4], для изготовления магнонных кристаллов [5]. Поликристаллические пленки уступают по характеристикам своим объемным аналогам, но они обнаруживают устойчивость к процессам формирования структур микроэлектроники на их основе. Активно исследуется железоиттриевый гранат (YIG) в наноструктурном состоянии [6,7] в связи с фундаментальными вопросами физики нанокристаллических магнетиков, так и перспективами их использования в покрытиях, нанокомпозитах с пьезоэлектрическими материалами для получения колоссального значения магнитоэлектрического эффекта [8-10]. Наноматериалы являются неравновесными системами с высоким уровнем дефектности. Точечные и иные дефекты оказывают сильное влияние на оптические и магнитные свойства YIG [11].

Нанокерамики YIG, приготовленные методом кручения под давлением обнаруживают большую дефектность, связанную с нарушением стехиометрии и валентного состояния катионов железа [11]. Двухвалентное состояние ионов железа образуется при допировании YIG четырехвалентными ионами, которые занимает октаэдрические позиции. Наличие ионов $\mathrm{Fe}^{2+}$ приводит к отрицательному магнитному дихроизму в $\mathrm{Nb}$ (YIG) [12]. Эти ионы образуют примесные состояния в запрещенной зоне и два канала проводимости в структуре феррита граната. Один канал проводимости связан с переносом электронов по $t 2 g$ состояниям $\mathrm{Fe}^{2+}$ и редкоземельным элементом $R e$ в октаэдрических позициях, другой с переходом электронов по тетраэдрам с рождением магнонов на редкоземельном элементе. Переходы электронов между ионами железа в тетра- и октаэдрических позициях связаны с рождением магнонов и с возможностью образования магнонного облака - ферронов $[13,14]$ при приближении к температуре магнитного фазового перехода. В этом случае транспортные характеристики будут зависеть от магнитного поля. Образование $\mathrm{Fe}^{2+}$ в ферритах гранатов возможно также в результате зарядовых флуктуаций. Так ферриты граната с церием обнаруживают зарядовые флуктуации $\mathrm{Ce}^{+3}-\mathrm{Fe}^{+3}=\mathrm{Ce}^{+4}-\mathrm{Fe}^{+2}$ с энергией щели $1.3 \mathrm{eV}[15]$. На интерфейсе и на границах кристаллитов флуктуации кристаллического поля приведут к уменьшению щели. Ионы церия обнаруживают промежуточную валентность 3.4 в $\mathrm{CeFe}_{2}$ [16]. Флуктуации валентности при замещении иттрия церием могут привести к росту проводимости, по сравнению с $\mathrm{Y}_{3} \mathrm{Fe}_{5} \mathrm{O}_{12}$.

Цель работы: выяснить дефектные состояния ионов и магниторезистивные эффекты в поликристаллической пленке $\mathrm{Ce}_{3} \mathrm{Fe}_{5} \mathrm{O}_{12}$.

\section{2. Рентгеноструктурный анализ, ИК- и оптическая спектроскопия}

Слои номинального состава $\mathrm{Ce}_{3} \mathrm{Fe}_{5} \mathrm{O}_{12}$ были получены методом ионнолучевого распыления на подложку галийгадолиневого граната (GGG) [17]. Пленка толщиной $400 \mathrm{~nm}$ поликристаллическая со средним размером зерна $60-70 \mathrm{~nm}$. 


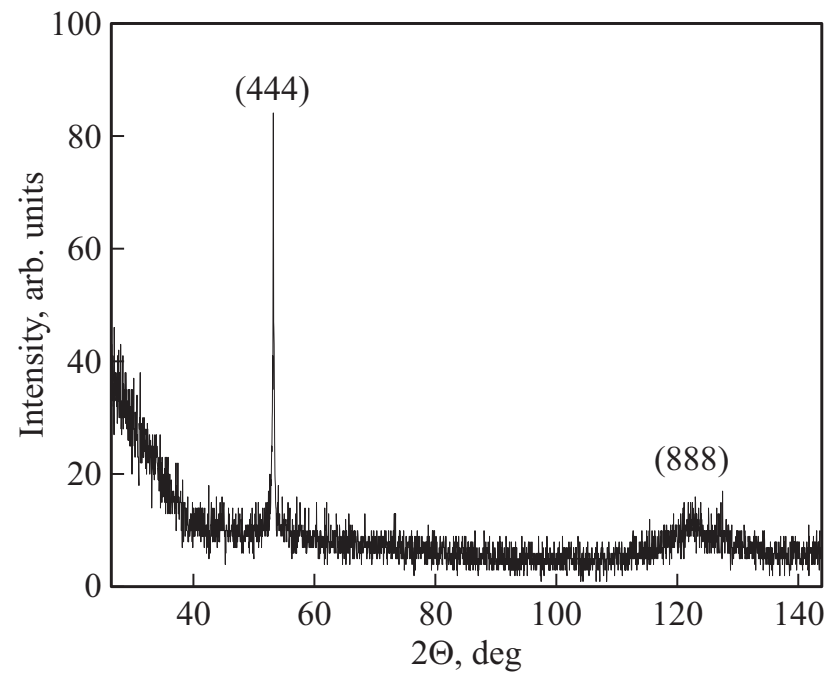

Рис. 1. Рентгенограмма пленки $\mathrm{Ce}_{3} \mathrm{Fe}_{5} \mathrm{O}_{12}$.

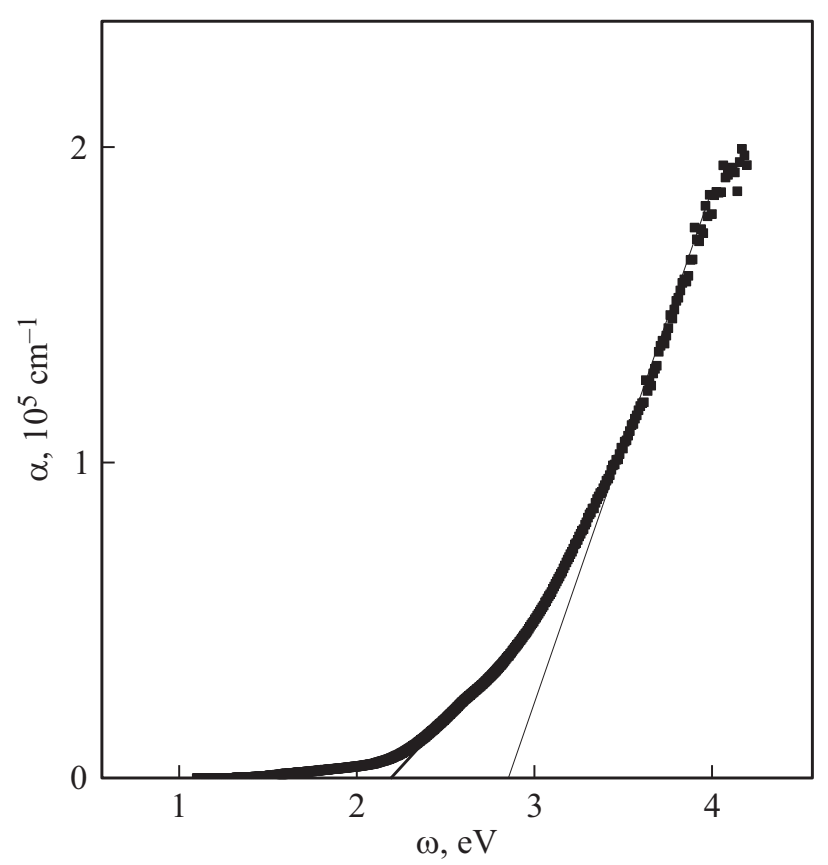

Pис. 2. Спектр поглощения пленки $\mathrm{Ce}_{3} \mathrm{Fe}_{5} \mathrm{O}_{12}$ от энергии фотонов.

Рентгенограмма пленки $\mathrm{Ce}_{3} \mathrm{Fe}_{5} \mathrm{O}_{12}$ представлена на рис. 1. Пленка $\mathrm{Ce}_{3} \mathrm{Fe}_{5} \mathrm{O}_{12}$ обладает кубической структурой пространственной группы S.G.: $\operatorname{Ia} 3 d(230)$ с преимущественной ориентацией в направлении (444). Параметр $a$ элементарной кубической ячейки пленки имеет величину $a=1.234 \mathrm{~nm}$. Кристаллическая структура пленки заметно деформирована $\left(\Delta a=a_{\text {substrate }}-a_{\text {film }}\right.$ $=0.05 \AA)$. В процентном отношении различие между параметрами решетки пленки и подложки составляет $\sim 0.4 \%$.

Спектр поглощения в оптическом диапазоне измерен на спектрофотометре Cary500Scan и представлен на рис. 2. Ширина запрещенной зоны $E_{g}=2.78 \mathrm{eV}$ [18].
Замещение иттрия церием приводит к незначительному уменьшению ширины запрещенной зоны по сравнению c $\mathrm{Bi}_{3} \mathrm{Fe}_{5} \mathrm{O}_{12}$ с $E_{g}=2.85 \mathrm{eV}[19]$ и YIG на гранате $3.1 \mathrm{eV}$. „Хвосты“ в интервале $2-2.8 \mathrm{eV}$ вызваны переходом электронов в кристаллическом поле тетраэдра с $\mathrm{Fe}^{3+}$ между мультиплетами ${ }^{6} A_{1} \rightarrow{ }^{4} T_{2},{ }^{4} A_{1},{ }^{4} E,{ }^{4} T_{2},{ }^{4} T_{1},{ }^{4} E$. Электронный переход с переносом заряда $2 p-3 d$ между ионами железа в октаэдрических и тетраэдрических позициях происходит при $2.8 \mathrm{eV}$.

Дефектные заряженные состояния определим из ИК-спектров (рис. 3, a). В ИК-спектре присутствуют две линии поглощения в области частот $\omega_{1} \sim 5520 \mathrm{~cm}^{-1}$ $\left(\lambda_{1} \sim 1.5 \mu \mathrm{m}\right)$ и $\omega_{2} \sim 6800 \mathrm{~cm}^{-1}\left(\lambda_{1} \sim 1.8 \mu \mathrm{m}\right)$. Одна линия на частоте $\omega_{1}$ исчезает при $275 \mathrm{~K}$, другая на частоте $\omega_{2}$ в области температур (360-400) K. Две линии перехода на длинах волн 1.95 и $2.15 \mu \mathrm{m}$ наблюдались в $\mathrm{Y}_{3} \mathrm{Fe}_{5} \mathrm{O}_{12}$ (YIG), легированным четырехвалентными ионами $\mathrm{Zr}$ [20] и $\mathrm{Pb}$ [21]. В работе [22] предложено объяснение, связанное с оптическими переходами в двухвалентном ионе железа в низкосимметричном кристаллическом поле. Триплетное ${ }^{5} T_{2 g}$ состояние ионов $\mathrm{Fe}^{2+}$ в октаэдре (тетраэдре) с триклинным искажением решетки расщепляется на дублет ${ }^{5} E_{g 1}$ и синглет $A_{g}$. В модели кристаллического поля с параметрами $10 D_{q}=9500 \mathrm{~cm}^{-1}$, тригонального расщепления $C=500 \mathrm{~cm}^{-1}$ вычислен электронный переход на $A_{g}-5 E_{g}$ на длине волны $1.54 \mu \mathrm{m}$ в октаэдре и на $1.66 \mu \mathrm{m}$ в тетраэдре. Длины волн зависят от параметров кристаллического поля и расположения ионов $\mathrm{Fe}^{2+}$ от дефектов. С изменением симметрии от тригональной к кубической эти переходы исчезают. В $\left(\mathrm{Y}_{1-x} \mathrm{Ce}_{x}\right) \mathrm{Fe}_{5} \mathrm{O}_{12}$ кристаллическая симметрия выше $170 \mathrm{~K}$ не меняется [23]. Можно предположить, что и в пленках $\mathrm{Ce}_{3} \mathrm{Fe}_{5} \mathrm{O}_{12}$ кристаллические фазовые переходы отсутствуют при нагревании.

Электронные переходы могут быть обусловлены зарядовыми флуктуациями ионов церия $\mathrm{Ce}^{3+}+\mathrm{Fe}^{3+} \rightarrow \mathrm{Ce}^{4+}+\mathrm{Fe}^{2+}$ с энергией перезарядки ионов $1.2 \mathrm{eV}$ в объеме кристалла. На поверхности пленки или вблизи дефектов с нарушением координационного числа ближайших соседей могут существовать ионы $\mathrm{Ce}^{4+}, \mathrm{Fe}^{2+}$, которые обнаружены мессбауровским методом в тетраэдрах [24]. Согласно ab initio расчетам, энергия для перераспределения зарядов на Се-О-связи находится в интервале $0.54-0.7 \mathrm{eV}$ [25]. Ионный радиус церия $\mathrm{Ce}^{3+}(1.14 \AA)$ больше радиуса $\mathrm{Ce}^{4+}(0.97 \AA)$ и радиус $\mathrm{Fe}^{2+}(0.63 \AA)$ превышает $\mathrm{Fe}^{3+}(0.49 \AA)$ в тетраэдрическом узле. Передача заряда индуцирует сокращение длины связи Се-О. Дипольные электронные переходы $d-f$ типа между ионами $\mathrm{Fe}^{2+}$ в тетраэдрических (октаэдрических) позициях и $\mathrm{Ce}^{4+}$ образуют две линии поглощения.

Линия поглощения на частоте $\omega_{1}$ исчезает при $275 \mathrm{~K}$ в результате делокализации электрона в области пары $\mathrm{Ce}^{4+}, \mathrm{Fe}^{2+}$ в октаэдре при деформации пленки относительно подложки. Делокализация электронов на $\mathrm{Fe}^{2+}$ в тетраэдре выше $360 \mathrm{~K}$ вызывает исчезновение перехода на частоте $\omega_{2}$. Дальнейший нагрев приводит 


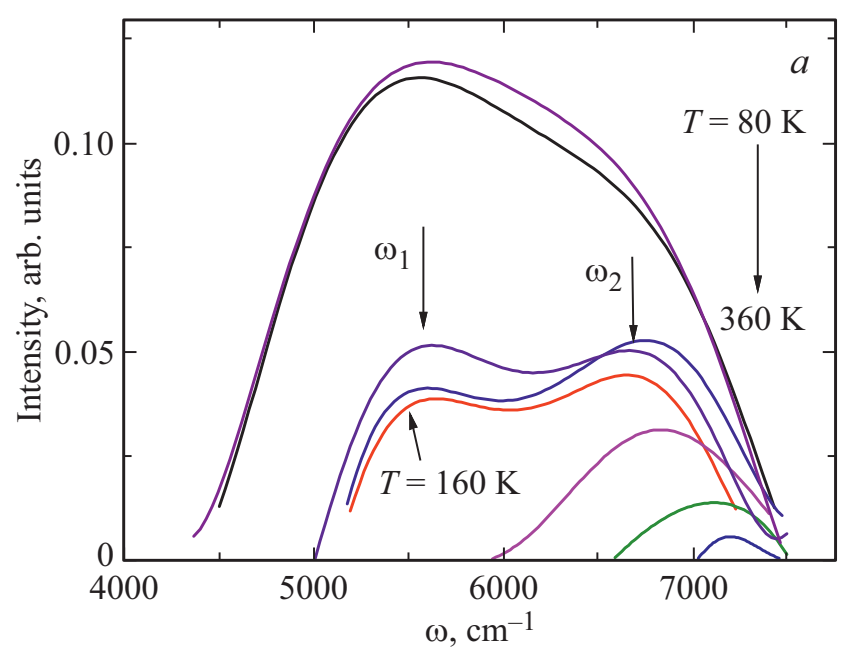

Рис. 3. ИК-поглощение пленки $\mathrm{Ce}_{3} \mathrm{Fe}_{5} \mathrm{O}_{12}$ в частотном интервале частотах $\omega_{1}(1)$ и $\omega_{2}(2)$ от температуры $(b)$.

к перескоку электронов между ионами $\mathrm{Fe}^{2+}$ в тетраэдрических и $\mathrm{Fe}^{3+}$ октаэдрических позициях. Температура $160 \mathrm{~K}$, при которой интенсивность ИК-поглощения пленки $\mathrm{Ce}_{3} \mathrm{Fe}_{5} \mathrm{O}_{12}$ резко уменьшается (рис. $3, b$ ), коррелирует с температурой спин-переориентационного перехода $170 \mathrm{~K}$ в $\left(\mathrm{Y}_{1-x} \mathrm{Ce}_{x}\right) \mathrm{Fe}_{5} \mathrm{O}_{12}[23]$.

\section{3. Электросопротивление, BAX и импеданс}

Электросопротивление было измерено четырехзондовым методом. Пленка является высокоомной и регистрация сопротивления начинается выше $350 \mathrm{~K}$ с $2 \mathrm{G} \Omega$ (рис. 4).

При $400 \mathrm{~K}$ уменьшается энергия активации от 0.27 до $0.18 \mathrm{eV}$. Сопротивление на переменном токе увеличивается при нагревании и достигает локального максимума

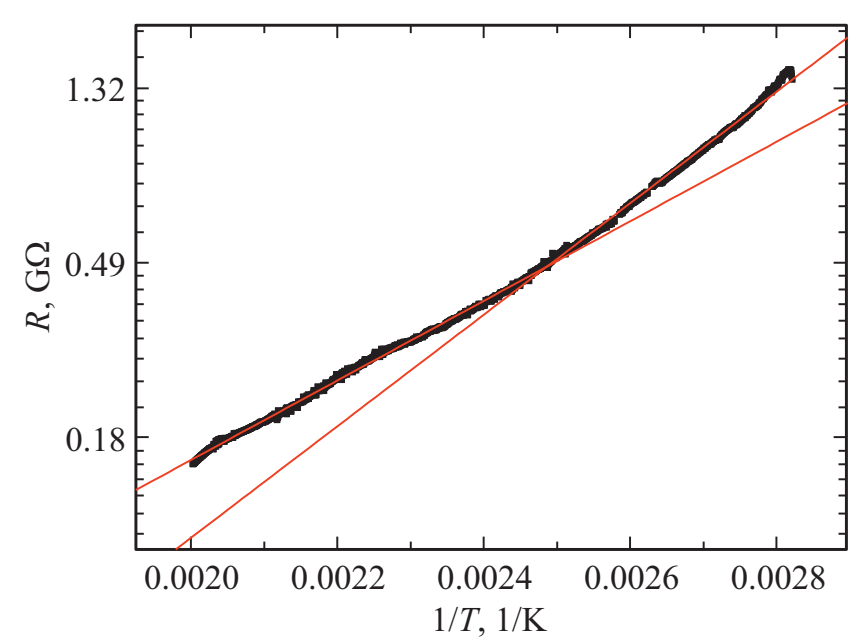

Рис. 4. Сопротивление пленки $\mathrm{Ce}_{3} \mathrm{Fe}_{5} \mathrm{O}_{12}$ от обратной температуры.

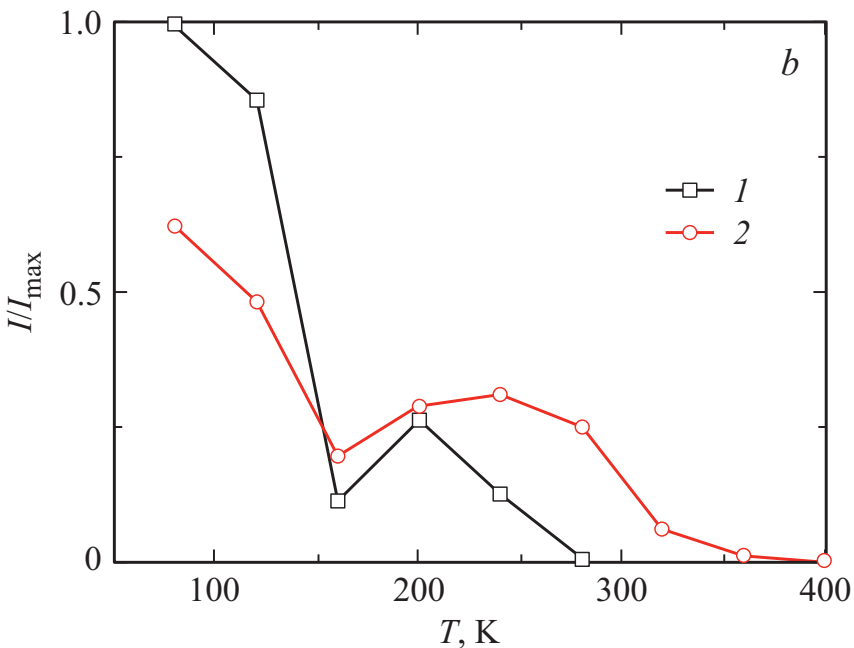

(a). Интенсивность поглощения на

с выходом на плато также при $400 \mathrm{~K}$, где импеданс имеет минимум (рис. 5). Минимум импеданса связан с исчезновением миграционной поляризации в результате делокализации электронов.

Частотные зависимости компонент импеданса в интервале частот $10^{2}-10^{6} \mathrm{~Hz}$ представлены на рис. 6 . Импеданс хорошо описывается степенной функцией от частоты $Z=A / \omega^{n}$. Реактивное сопротивление определяется индуктивным вкладом $X_{L}=L \omega$ и емкостным $X_{c}=1 / C \omega$. Подгонка экспериментальных данных дает $n=1.0 \pm 0.02$ в интервале температур $300-500$ К. Т. е. реактивное сопротивление определяется локализованными зарядами и емкостью пленки $(C): \operatorname{Im} Z(\omega)=1 / C \omega$. При $400 \mathrm{~K}$ минимум импеданса связан с максимумом емкости, вызванный исчезновением дипольных моментов пар $\mathrm{Ce}^{4+}, \mathrm{Fe}^{2+}$ в тетраэдре. Изменение импеданса в магнитном поле не превышает $0.1 \%$. Активное сопротивление также описывается степенной зависимостью $\operatorname{Re}(Z(\omega))=B / \omega^{n}$, где показатель степени растет от $n=0.95 \pm 0.04$ до $1.22 \pm 0.03$ при нагревании до $500 \mathrm{~K}$. Сопротивление зависит от частоты измерений, что свидетельствует о прыжковом механизме переноса зарядов. Зависимость проводимости от частоты в этом случае описывается выражением $\sigma=\sigma_{0} \omega^{s}$, где $s=0.8$ [26], которое описывает прыжковую перезарядку дефектов одного типа. Сопротивление на переменном токе увеличивается в магнитном поле и уменьшается выше $450 \mathrm{~K}$ (см. рис. 7).

Вольт-амперные характеристики (BAX) пленок в интервале температур 300-500 K и магнитных полей до $8 \mathrm{kOе}$ приведены на рис. 8. Зависимости $I(U)$ являются линейными, гистерезис отсутствует. Проводимость подчиняется закону Ома. Изменение тока (сопротивления) в магнитном поле не превышает $0.5 \%$. Магнитосопротивление на постоянном токе на порядок меньше, чем на переменном токе. 

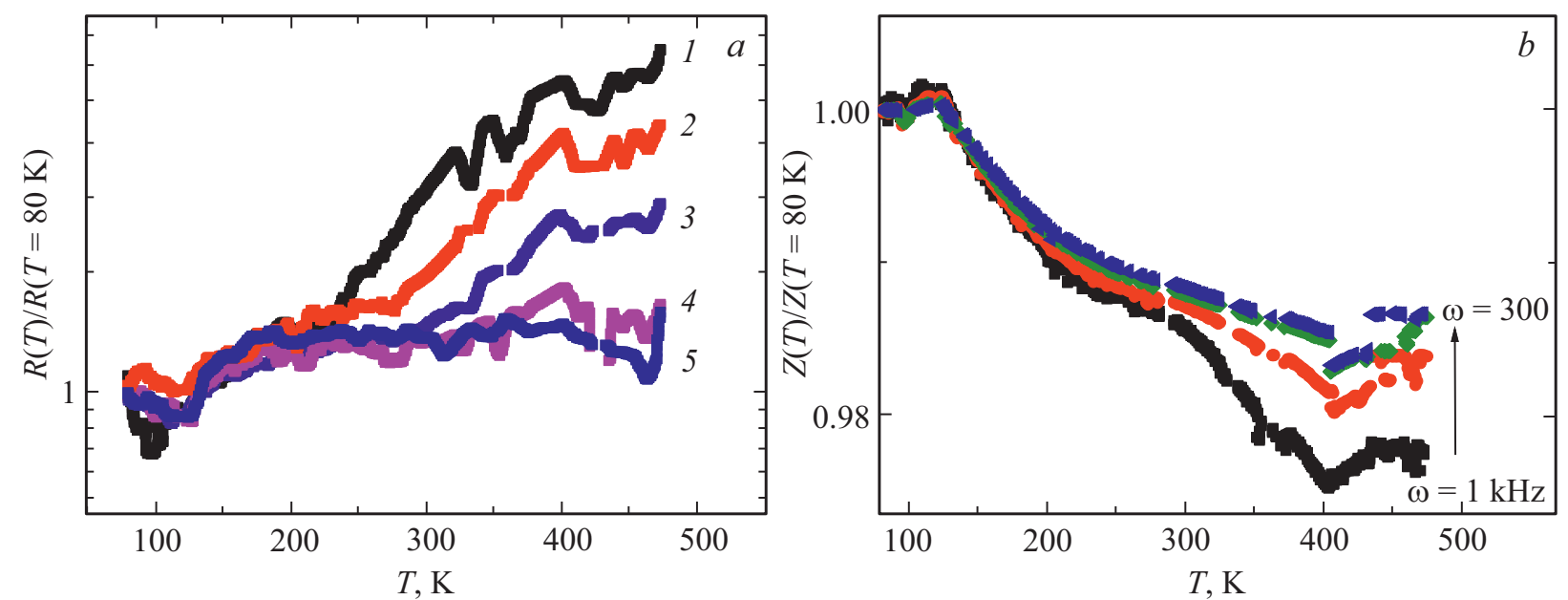

Рис. 5. Нормированные значения реальной части импеданса на $\operatorname{Re}(Z(T=80 \mathrm{~K}))(a)$ и импеданса на $Z(T=80 \mathrm{~K})(b)$ от температуры на частотах $\omega=1 \mathrm{kHz}(1), 5 \mathrm{kHz}(2), 10 \mathrm{kHz}(3), 50 \mathrm{kHz}(4), 100 \mathrm{kHz}(5), 300 \mathrm{kHz}(6)$.
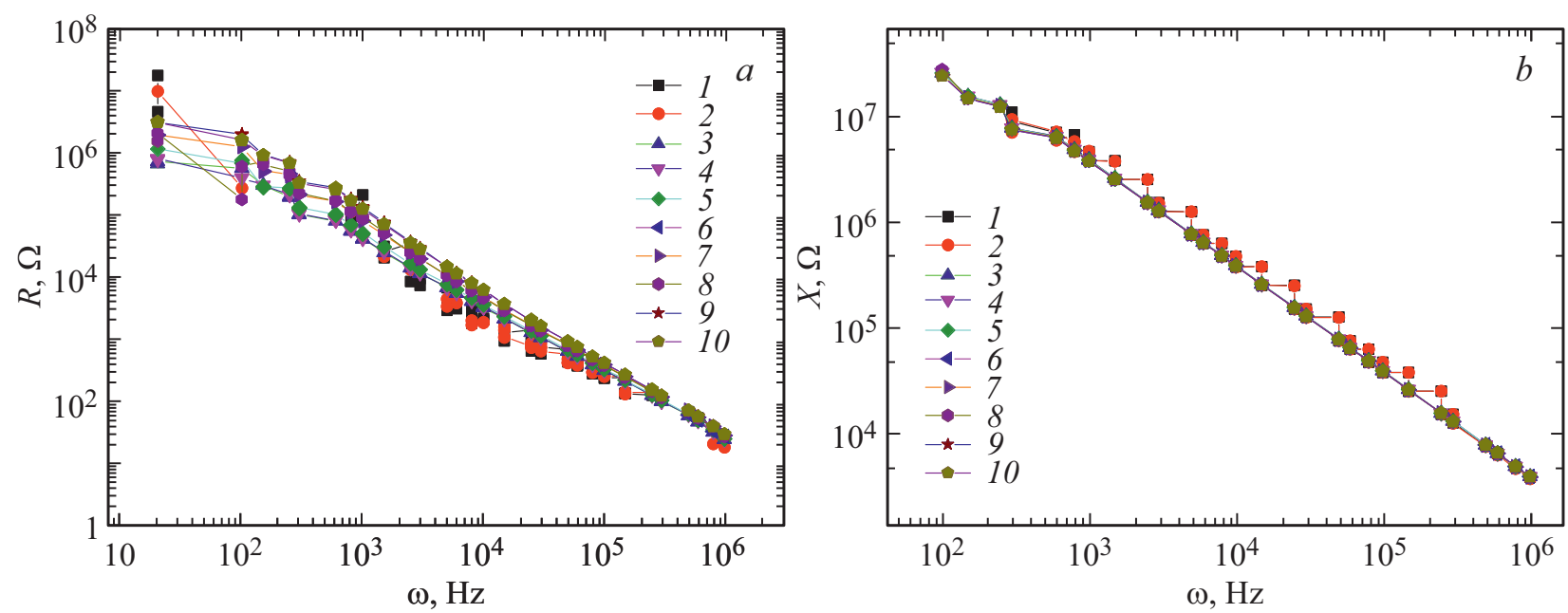

Рис. 6. Активное $(a)$ и реактивное $(b)$ сопротивления пленки $\mathrm{Ce}_{3} \mathrm{Fe}_{5} \mathrm{O}_{12}$ без поля $(1,3,5,7,9)$ и в магнитном поле $8 \mathrm{kOe}(2,4,6,8,10)$ при температурах $T=300 \mathrm{~K}(1,2), 350 \mathrm{~K}(3,4), 400 \mathrm{~K}(5,6), 450 \mathrm{~K}(7,8), 500 \mathrm{~K}(9,10)$.

\section{4. Модель}

Температурные зависимости ИК-спектров и проводимости объясним наличием двухвалентных ионов железа. Пленки при замещении иттрия церием Ce:YIG/GGG обнаруживают ромбоэдрическое искажение и изменение взаимного расположения октаэдров и тетраэдров [23,27]. Тетраэдры более подвержены деформации, чем октаэдры. Параметр псевдокубической постоянной решетки растет при нагревании выше $170 \mathrm{~K}$ и при этой температуре реализуется спин-переориентационный переход легкая ось-легкая плоскость [23]. В ИК-спектpax наблюдаются две линии поглощения, связанные с переходом электронов между катионами $\mathrm{Fe}^{2+}$ в октаэдрах и тетраэдрах и ионом $\mathrm{Ce}^{4+}$. Изменение угла ромбоэдрического искажения меняет угол между связями $\mathrm{Fe}^{2+}-\mathrm{O}$ и $\mathrm{O}-\mathrm{Ce}^{4+}$ и величину потенциального барьера при туннелировании электронов между катио- нами. Резкое уменьшение интенсивности электронных переходов в ИК-спектрах вызвано уменьшением коэффициентов туннелирования $D_{1} / D_{2}=\exp \left(\Delta_{2}-\Delta_{1}\right) \sim 5$ в окрестности $160 \mathrm{~K}$.

При нагревании выше 160 К возникает тангенциальноая составляющая напряжения вдоль интерфейса пленкаподложка. Так в Ce:YIG/GGG коэффициент теплового расширения пленки растет быстрее по сравнению с подложкой при $T>170 \mathrm{~K}$, проходит через максимум при $210 \mathrm{~K}$ и меняет знак при $284 \mathrm{~K}$. Изменение знака упругого напряжения со стороны подложки на пленку приводит к делокализации электрона в $\mathrm{Fe}^{2+}$ в октаэдре. В ИК-спектре остается одна линия поглощения при переходе электронов между катионами $\mathrm{Fe}^{2+}-\mathrm{Ce}^{4+}$ в тетраэдре. В интервале температур $360-400 \mathrm{~K}$ усиливаются зарядовые флуктуации $\mathrm{Ce}^{4+}+\mathrm{Fe}^{2+} \rightarrow \mathrm{Ce}^{3+}+\mathrm{Fe}^{3+}$, что приводит к исчезновению линии поглощения на частоте $\omega_{2}$. 


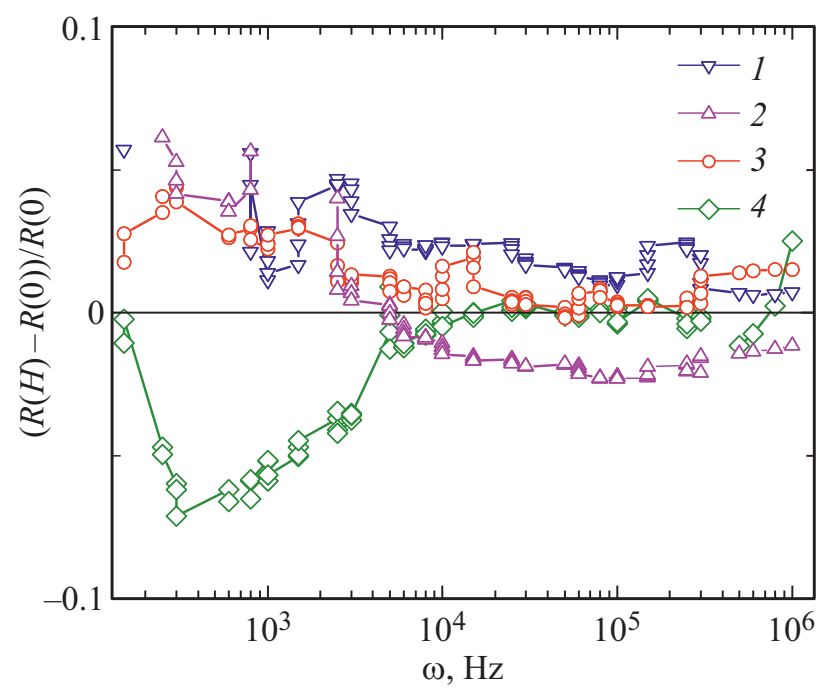

Рис. 7. Магнитосопротивление $((R(H)-R(0)) / R(0)$ от частоты при $T=300 \mathrm{~K}(1), 350 \mathrm{~K}(2), 450 \mathrm{~K}(3), 500 \mathrm{~K}(4)$.

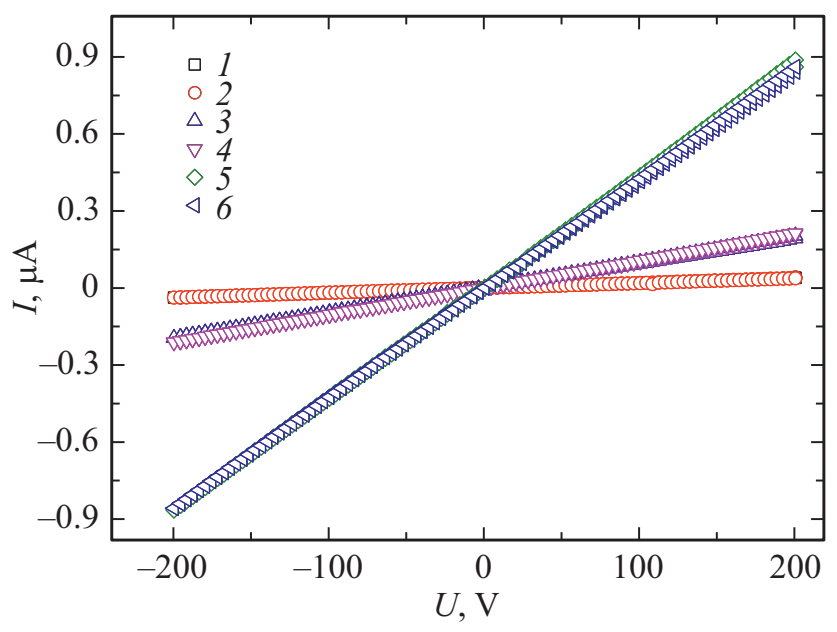

Рис. 8. ВАХ пленки $\mathrm{Ce}_{3} \mathrm{Fe}_{5} \mathrm{O}_{12}$ без поля $(2,4,6)$ и в магнитном поле $8 \mathrm{kOe}(1,3,5)$ при температурах $T=400 \mathrm{~K}(1,2)$, $450 \mathrm{~K}(3,4), 500 \mathrm{~K}(5,6)$.

Рассмотрим качественное отличие магнитосопротивления на постоянном и переменном токе, которое отличается более чем на порядок. Проводимость на переменном токе в неупорядоченной среде связана с диэлектрической проницаемостью $\sigma(\omega, \mathbf{r})=i \omega \varepsilon(\omega, \mathbf{r})$, где $\sigma$ - тензор проводимости, $\varepsilon-$ локальная диэлектрическая функция. В приближении $1 / \omega$ больше времени рассеяния, тензор проводимости в поперечном магнитном поле $H^{Z}$ связан соотношением

$$
\hat{\sigma}(\omega)=\frac{\sigma}{1+\beta^{2}}\left(\begin{array}{cc}
1 & \beta \\
-\beta & 1
\end{array}\right)+i \omega \varepsilon
$$

где $\beta=\mu H, \mu-$ подвижность. В случае прыжкового механизма проводимости с равномерным распределением носителей тока по пленке диагональная компонента проводимости зависит от частоты через продольный диэлектрический отклик [28]:

$$
\operatorname{Re}\left[\varepsilon_{x x}(\omega)\right]=\frac{\varepsilon\left(1-\beta^{2}+(\omega \tau)^{2}\left(1+\beta^{2}\right)^{2}\right)}{1+(\omega \tau)^{2}\left(1+\beta^{2}\right)^{2}},
$$

где $\tau=\varepsilon / \sigma$. С ростом поля $\varepsilon_{x x}$ уменьшается, сопротивление растет в магнитном поле. При приближении к температуре Кюри образуются ферроны, области с локальным ферромагнитным упорядочением спинов в тетраэдрических и октаэдрических узлах. Наличие электрически неоднородных состояний приводит к росту диэлектрической проницаемости в магнитном поле. В двухфазной системе с предельными параметрами с $\sigma_{1}=0, \varepsilon=\varepsilon_{1}$, с концентрацией $x$ и $c \sigma_{2}=\sigma, \varepsilon=0 \mathrm{c}(1-x)$ найдено численное решение для диэлектрического отклика от частоты при фиксированных магнитных полях в двумерной двухкомпонентной среде, которое можно аппроксимировать в виде $\varepsilon(\beta, \omega) \sim(\omega)+A(\omega) \beta^{1 / 2}[28]$.

\section{5. Заключение}

Найдены две линии поглощения в ИК-спектре и температуры их исчезновения, которые связываются с электронными переходами между примесными состояниями ионов двухвалентного железа в октаэдрических (тетраэдрических) позициях и четырехвалентного церия. Установлена температура минимума импеданса и изменение энергии активации, вызванные исчезновением миграционной поляризации. Обнаружена смена знака магнитосопротивления на переменном токе при приближении к температуре Кюри, которое объясняется образованием электрически неоднородных состояний.

\section{Благодарности}

Авторы признательны А.И. Стогнию из Научно-практического центра по материаловедению НАН Беларуси за предоставленные образцы.

\section{Финансирование работы}

Исследование выполнено при финансовой поддержке Российского фонда фундаментальных исследований, Правительства Красноярского края, Красноярского краевого фонда науки в рамках научного проекта № 18-42-240001 „Инверсия знака компонент магнитоэлектрического тензора по температуре в пленках висмутового феррита граната замещенного неодимом“.

\section{Конфликт интересов}

Авторы заявляют, что у них нет конфликта интересов. 


\section{Список литературы}

[1] X. Ma. J. Mater. Sci.: Mater. Electron. 11, 351 (2000).

[2] M.C. Onbasli, T. Goto, X. Sun, N. Huynh, C.A. Ross. Opt. Exp. OE 22, 25183 (2014).

[3] M. Huang, S-Y. Zhang. Appl. Phys. A 74, 177 (2002).

[4] M. Vasiliev, P.C. Wo, K. Alameh, P. Munroe, Z. Xie, V.A. Kotov, V.I. Burkov. J. Phys. D 42, 135003 (2009).

[5] A.B. Ustinov, A.V. Drozdovskii, A.A. Nikitin, A.A. Semenov, D.A. Bozhko, A.A. Serga, B. Hillebrands, E. Lähderanta, B.A. Kalinikos. Commun. Phys. 2, 1 (2019).

[6] J.W. Lee, J.H. Oh, J.C. Lee, S.C. Choi. J. Magn. Magn. Mater. 272-276, 2230 (2004).

[7] X.Z. Guo, B.G. Ravi, Q.Y. Yan, R.J. Gambino, S. Sampath, J. Margolies. J. Parise Ceram. Int. 32, 61 (2006).

[8] A.M.J.G. Run, D.R. Terrell, J.H. Scholing. J. Mater. Sci. 9, 10, 1710 (1974).

[9] J. Boomgaard, A.M.J.G. Run, J. Suhtelen. Ferroelectrics 10, 1/4, 295 (1976).

[10] А.Е. Гелясин, В.М. Лалетин, Л.И. Трофимович. ЖТФ 58, 11, 2239 (1988).

[11] Б.А. Гижевский, Ю.П. Сухоруков, Е.А. Ганьшина, Н.Н. Лошкарева, А.В. Телегин, Н.И. Лобачевская, В.С. Гавико, В.П. Пилюгин. ФТТ 51, 9, 1729 (2009).

[12] B. Antonini, S. Geller, A. Paoletti, P. Paroli, A. Tucciarone. Phys. Rev. Lett. 41, 1556 (1978).

[13] Э.Л. Нагаев. УФН 117, 437 (1975).

[14] М.Ю. Каган, К.И. Кугель. УФН 171, 577 (2001).

[15] M. Huang, S-Y. Zhang. Appl. Phys. A 74, 177 (2002).

[16] Ю.П. Смирнов, А.Е. Совестнов, А.В. Тюнис, В.А. Шабуров. ФТТ 40, 8, 1397 (1998).

[17] G.D. Nipan, A.I. Stognij, V.A. Ketsko. ChemInform Abstract: Oxide Ferromagnetic Semiconductors. Coatings and Films ChemInform 44 (2013).

[18] J.I. Pankove. Optical processes in semiconductors (1971).

[19] S.H. Wemple, S.L. Blank, J.A. Seman, W.A. Biolsi. Phys. Rev. B 9, 2134 (1974).

[20] F. Lucari, C. Mastrogiuseppe, E. Terrenzio, G. Tomassetti. J. Magn. Magn. Mater. 20, 84 (1980).

[21] F. Lucari, C. Mastrogiuseppe, G. Tomassetti. J. Phys. C 10, 4869 (1977).

[22] Z.V. Gareyeva, R.A. Doroshenko. J. Magn. Magn. Mater. 268, 1 (2004).

[23] E. Lage, L. Beran, A.U. Quindeau, L. Ohnoutek, M. Kucera, R. Antos, S.R. Sani, G.F. Dionne, M. Veis, C.A. Ross. APL Mater. 5, 036104 (2017).

[24] X. Guo, A.H. Tavakoli, S. Sutton, R.K. Kukkadapu, L. Qi, A. Lanzirotti, M. Newville, M. Asta, M. Navrotsky. Chem. Mater. 26, 1133 (2014).

[25] M.M. Branda, C. Loschen, K.M. Neyman, F. Illas. J. Phys. Chem. C 112, 17643 (2008).

[26] S.N.F. Mott, E.A. Davis. Electronic Processes in Noncrystalline Materials. Clarendon Press (1971).

[27] A. Kehlberger, K. Richter, M.C. Onbasli, G. Jakob, D.H. Kim, T. Goto, C.A. Ross, G. Götz, G. Reiss, T. Kuschel, M. Kläui. Phys. Rev. Appl. 4, 1, 014008 (2015).

[28] M.M. Parish, P.B. Littlewood. Phys. Rev. Lett. 101, 166602 (2008).

Редактор К.В. Емиев 